\title{
Self-state representations: Patterns of interconnected beliefs with specific holistic meanings and importance
}

\author{
E. TORY HIGGINS \\ Columbia University, New York, New York
}

\begin{abstract}
Self-discrepancy theory proposes that distinct relations among different self-state representations (e.g., the actual, ideal, ought, and can selves) can produce distress. Like cybernetic theory, it assumes that people self-regulate through a discrepancy-reducing feedback process. Like cognitive neuroscience theory, it assumes that the internal representations are interconnected such that activation of one element can initiate the running off of established patterns. Like Gestalt psychology, it assumes that each pattern has a meaning and importance that is not deducible from knowledge of the isolated elements. Together, these assumptions yield predictions that pose challenges for simple theories of knowledge representation. Evidence for two such predictions is presented: (1) Exposure to positive input can produce distress; and (2) the same belief can produce more distress when combined with a positive than with a negative belief.
\end{abstract}

Perhaps the most fundamental psychological characteristic of people is that they derive meanings from the events in their lives and then respond to those meanings. This insight into the nature of people has a long history in Western thought, but it was most clearly developed at the turn of the century in the work of Weber, Durkheim, Freud, James, Cooley, and others. Social objects and events not only have meaning. They also have importance The meaning and importance of subjective experience are both captured in the concept of psychological significance. Socialization histories can cause certain psychological significances to become available and chronically accessible, and these chronic psychological significances are a major source of individual, developmental, and cultural differences in how people respond to the social world. This paper is concerned with the particular case of chronic psychological significances associated with the self-system.

In recent years, my colleagues and I have developed a theory of how various kinds of relations among individuals' representations of different types of self-states are a vulnerability factor for distinct kinds of distress. Selfdiscrepancy theory (Higgins, 1987; 1989b) distinguishes between people's representations of their current or actual selves and their representations of valued end states or self-directive standards. The former representation is the self-concept, and the latter representations are selfguides. The theory distinguishes between two basic types of self-guides: (1) an ideal self-guide-one's representation of the attributes that someone (oneself or another) would like one, ideally, to possess (i.e., hopes, wishes, or aspirations); and (b) an ought self-guide-one's

The author's mailing address is Department of Psychology, Schermerhorn Hall, Columbia University, New York, NY 10027. representation of the attributes that someone (oneself or another) believes one should or ought to possess (i.e., a representation of a sense of one's duty, obligations, or responsibilities).

Self-discrepancy theory shares some basic assumptions with three classic models of knowledge representation and their psychological significance. With cybernetic theory (e.g., Wiener, 1948), it shares the assumption that people self-regulate through a discrepancy-reducing negative feedback process, the function of which is to minimize differences between a current state of affairs and some other reference value. Self-discrepancy theory assumes that persons are motivated to bring their current states into line with some valued end state, to reach a condition in which their current actual selves match their self-guides.

With cognitive neuroscience theory (e.g., Hebb, 1949), self-discrepancy theory shares the assumption that the internal representations of stimuli can be conceptualized as massive interconnections of neural networks where the activation of one set of stimuli can initiate the running off of established ensembles of nerve cells ("cell assemblies" or "phase sequences"). Based upon the "synapse" model of knowledge accesibility and activation (see Higgins, 1989a), self-discrepancy theory assumes that the likelihood of a self-discrepancy's being activated and producing distress depends on general principles governing activation, such as connection strengths, activation thresholds, and excitatory interactions.

With Gestalt psychology (e.g., Koffka, 1935; Kohler, 1929), self-discrepancy theory assumes that psychological phenomena occur as part of a system of coexisting and mutually interdependent elements that has a meaning and importance that are not deducible from knowledge of the isolated elements of the system. Self-discrepancy theory assumes that a particular pattern of self-beliefs, 
as a whole, has a distinct psychological significance that depends on the interrelations among the self-beliefs and not just the psychological significance of the self-beliefs as independent elements.

Together, these assumptions provide the underpinnings of a model of patterned representations of self-state interrelations that yield predictions about psychological phenomena that pose challenges for simple theories of knowledge representation. Two such phenomena will be considered in this paper: (1) the production of distress from exposure to positive input; and (2) the production of greater distress when a belief is combined with a relatively positive belief than when it is combined with a relatively negative belief.

In most of our studies, introductory psychology undergraduates filled out a "Selves Questionnaire" that was included in a general battery of measures handed out at the beginning of the semester; 4-8 weeks later, the dependent measures were collected during an experimental session. The "Selves Questionnaire" simply asks respondents to list up to 8 or 10 attributes for each of a number of different self-states. It is administered in two sections, the first involving the respondent's own standpoint and the second involving the standpoints of the respondent's significant others (e.g., mother, father). On the first page of the questionnaire, the different types of selves are defined (e.g., the actual, ideal, and ought self-states). On each subsequent page, there is a question about a different self-state, such as, "Please list the attributes of the type of person you think you actually are," or "Please list the attributes of the type of person your Mother thinks you should or ought to be." Each respondent was also asked to rate, for each listed attribute, the extent to which the standpoint person (self or other) believed that the respondent actually possessed that attribute, ought to possess that attribute, wanted the respondent ideally to possess that attribute, and so on.

The basic coding procedure for calculating the magnitude of a self-discrepancy involved a two-step procedure:

1. For each self-discrepancy, the attributes in one selfstate (e.g., actual/own) were compared to the attributes in the other self-state (e.g., ideal/mother), to determine which attributes were synonyms and which were antonyms according to Roget's Thesaurus. Attributes across the two self-states that were neither synonyms nor antonyms (i.e., attributes in one self-state that had no relation to the attributes in the other self-state) were considered to be nonmatches. Antonyms were considered to be antonymous mismatches. Synonyms whose attributes had the same basic extent ratings were considered to be matches. Synonyms whose attributes had very different extent ratings (e.g., actual/own: "slightly attractive" versus ideal/mother: "extremely attractive") were considered to be synonymous mismatches.

2 . The magnitude of self-discrepancy for the two selfstates was calculated by summing the total number of mismatches and subtracting the total number of matches.
In order for people to experience the psychological significance associated with a particular self-belief pattern, the self-belief pattern must be activated. As with any stored social knowledge (see Higgins, 1989a), various factors can increase the likelihood that a self-belief pattern will be activated. One such factor is contextual priming of an element of the pattern.

If self-belief patterns consist of interconnected elements, as has been hypothesized here, then it should also be possible to activate an entire pattern by activating only one of its parts. Thus, activation of a self-guide that is part of an actual:self-guide discrepancy should, through spreading activation among interconnected parts, be sufficient to activate the whole discrepancy and induce distress even though the self-guide itself is subjectively positive (i.e., is a valued self-end-state). In addition, the greater the accessibility of a particular type of self-belief pattern, the more likely it is that the individual possessing the pattern will experience the psychological significance represented in that pattern. Thus, if an individual possesses more than one type of self-discrepancy, that individual should experience the emotional/motivational state associated with whichever self-discrepancy is temporarily more accessible.

An actual:ideal discrepancy, as a whole, represents the absence of positive outcomes (i.e., the nonobtainment or loss of hopes and wishes). This psychological situation is associated in turn with a dejected motivational state. Therefore, when an actual:ideal discrepancy is more accessible, individuals should experience a dejection-related syndrome (i.e., sadness, discouragement, psychomotor retardation). An actual:ought discrepancy, as a whole, represents the (expected) presence of negative outcomes (i.e., the expectation of punishment for having violated duties and responsibilities). This psychological situation is associated in turn with an agitated motivational state. Therefore, when an actual:ought discrepancy is more accessible, individuals should experience an agitation-related syndrome (i.e., worry, nervousness, psychomotor agitation). These predictions have been tested in a study by Higgins, Bond, Klein, and Strauman (1986, Study 2).

Undergraduates completed the "Selves Questionnaire" 4-6 weeks before the experimental session. On the basis of their responses, two groups of subjects were recruited for the experiment: (1) subjects who were relatively high on both actual:ideal discrepancy and actual:ought discrepancy; and (2) subjects who were relatively low on both types of discrepancies. Ostensibly as part of a lifespan developmental study, the subjects were asked either to describe the kind of person that they and their parents would ideally like them to be, the attributes that they hoped they would have (the ideal priming condition), or to describe the kind of person that they and their parents believed they ought to be, the attributes that they believed it was their duty or obligation to have (the ought priming condition). Both before and after this priming manipulation, the subjects filled out a mood questionnaire that iden- 
Table 1

Mean Change in Dejection-Related Emotions and Agitation-Related Emotions as a Function of Level of Self-Concept Discrepancies and Type of Priming

\begin{tabular}{|c|c|c|c|c|}
\hline \multirow{2}{*}{$\begin{array}{l}\text { Self-Concept } \\
\text { Discrepancies }\end{array}$} & \multicolumn{2}{|c|}{ Ideal Priming } & \multicolumn{2}{|c|}{ Ought Priming } \\
\hline & Dejection & Agitation & Dejection & Agitation \\
\hline $\begin{array}{l}\text { High actual:ideal and } \\
\text { actual:ought } \\
\text { discrepancies }\end{array}$ & 3.2 & -0.8 & 0.9 & 5.1 \\
\hline $\begin{array}{l}\text { Low actual:ideal and } \\
\text { actual:ought } \\
\text { discrepancies }\end{array}$ & -1.2 & 0.9 & 0.3 & -2.6 \\
\hline
\end{tabular}

Note-Each emotion was measured on a 6-point scale, ranging from "not at all" to "a great deal," and there were eight dejection emotions and eight agitation emotions. The more positive the number, the greater the increase in discomfort.

tified both dejection-related emotions and agitation-related emotions, and the subjects rated the extent to which they were then feeling each emotion.

As is shown in Table 1, the results of the study revealed a significant three-way interaction that was consistent with our predictions. For the subjects who had selfdiscrepancies available to be activated (i.e., the subjects who were high in both types of self-discrepancies), activation of a self-guide through priming was sufficient to produce an increase in discomfort. Moreover, the kind of discomfort that these subjects experienced depended on which type of self-guide was activated. As had been predicted, the subjects experienced an increase in dejection-related emotions when the ideal self-guide was activated, and an increase in agitation-related emotions when the ought self-guide was activated.

If self-discrepancy patterns are fully unitized cognitive structures (Hayes-Roth, 1977), as their hypothesized wholistic nature might suggest, then it should be possible to activate the entire pattern by simply activating a single element in the pattern, even if that element in itself is subjectively positive. Strauman and Higgins (1987) used a covert, idiographic priming technique to activate selfattributes in a task designed supposedly to investigate the "physiological effects of thinking about other people." Subjects were given phrases of the form, "An X person is __ (where $\mathrm{X}$ would be a trait adjective such as friendly or intelligent), and they were asked to complete each sentence as quickly as possible. For each sentence, each subject's total verbalization time and skin conductance amplitude were recorded. The subjects also reported their moods on scales measuring dejection-related and agitation-related emotions at both the beginning and the end of the session. The subjects were preselected on the basis of their responses to the "Selves Questionnaire," obtained weeks before the experimental session. Subjects were selected who were either high in actual:ideal discrepancy and low in actual:ought discrepancy, or high in actual:ought discrepancy and low in actual:ideal discrepancy.

In one of the studies, the subjects were primed either with positive self-guide attributes from which the subjects' actual self-attributes were discrepant (i.e., priming of mismatching, self-related attributes) or with positive attributes that did not appear among the subjects' listed actual self-attributes (i.e., priming of self-unrelated attributes). But in all conditions, the primed attribute was positive. (For other comparison and control conditions, see Strauman \& Higgins, 1987). As had been predicted, the study resulted in a dejection-related syndrome (i.e., mood, skin conductance amplitude, and total verbalization time all changing in the dejection-related direction) for the actual:ideal discrepant subjects and an agitation-related syndrome for the actual:ought discrepant subjects.

For the standardized skin conductance amplitude measure and the total verbalization time measure, this study permitted a trial-by-trial analysis of the effects of priming self-related mismatches. These results are shown in Figures 1 and 2 . As is evident from these figures, there was a striking shift into and out of the syndromes when subjects received subject-related mismatching priming versus subject-unrelated priming, respectively. As had been predicted, the direction of the shift for the actual:ideal discrepant subjects was opposite to that for the actual:ought discrepant subjects. This study demonstrates even more clearly how exposure to positive input can produce distress if the positive input activates a positive stored element that is a component of a larger pattern of

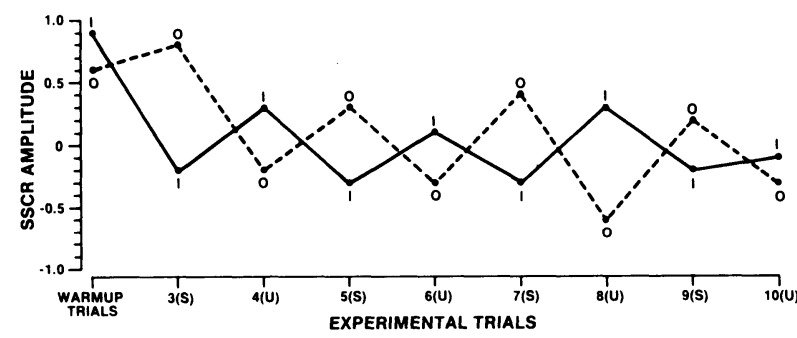

Figure 1. Standardized spontaneous skin conductance response amplitude during warm-up and experimental trials, for subjects in the mismatch priming condition. (I = actual/own:ideal/owndiscrepant subjects' central tendency. $O=$ actual/own:ought/otherdiscrepant subjects' central tendency. $\mathbf{S}=$ subject-related trial. $\mathbf{U}=$ subject-unrelated trial.)

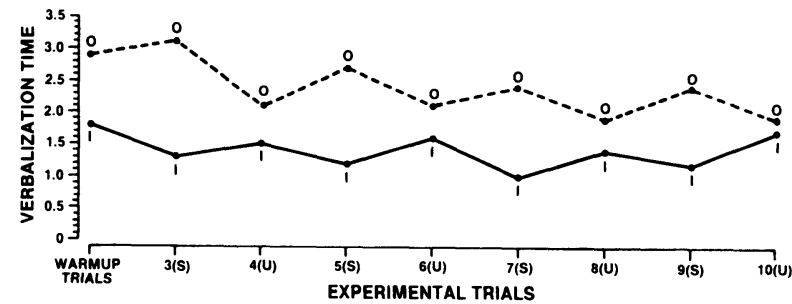

Figure 2. Total verbalization time (in seconds) during warm-up and experimental trials, for subjects in the mismatch priming condition. (I = actual/own:ideal/own-discrepant subjects' central tendency. $O=$ actual/own:ought/other-discrepant subjects' central tendency. $S=$ subject-related trial. $U$ = subject-unrelated trial.) 
stored elements that, as a whole, has negative psychological significance.

The patterns examined in the two studies just described were relatively simple, in that they were composed of only two elements. What would happen if a third element were added? Would not the distress be greater when the additional element was subjectively negative than when it was positive? Again, the assumptions of self-discrepancy theory suggest that the distress could be greater when the third element was positive if the meaning of the whole pattern became more negative as a consequence of its addition. This possibility has been investigated in a recent study by Higgins, Tykocinsky, and Vookles (1990).

Descriptions of self-beliefs in the literature have not been restricted to the self-concept (the current actual self) or to self-guides. The literature has also described people's beliefs about what they can and cannot do, as well as people's beliefs about what type of person they might become or expect to become. These "potential" (James, 1890/1948) or "possible" (Markus \& Nurius, 1986) actual selves have been described as having important motivational effects (Bandura, 1982; Markus \& Nurius, 1987; for a review, see Markus \& Wurf, 1987). Previous models, however, have not considered the psychological significance of the relations between these types of self-beliefs and other types of self-beliefs.

In order to consider the implications of such additional types of self-beliefs, self-discrepancy theory has recently been expanded to include the following self-domain: the can self, which is one's representation of the attributes that someone (oneself or another) believes one can possess (i.e., a representation of someone's beliefs about one's capabilities or potential). The can self is not an additional self-guide. Indeed, some people possess a can self that is discrepant with the end states that they value (e.g., they do not believe that they have the potential to fulfill their ideal). The can self is also not the same as the actual self. Some people believe that their potential selves are quite different from their current selves. Rather than represent either a current self-state or a valued end state, the can self represents a view of some actual end state to come-a prospective self-state.

The purpose of including a distinct can self in selfdiscrepancy theory was to identify new self-belief patterns that are associated with specific vulnerabilities. As described earlier, an actual:ideal discrepancy is a twoelement relation representing the subjective belief that one's current attributes have chronically failed to fulfill one's hopes, wishes, or aspirations. This relation represents the general psychological situation of absence of positive outcomes. This general psychological situation, in turn, is associated with dejection-related feelings. If one should add a third element to this relation, creating a multiple-element pattern, would this general psychological situation take on a more specific meaning? We felt that addressing this question for the actual:ideal relation was especially interesting and important, because the voluminous literature on self-esteem has traditionally fo- cused on this particular relation without considering the implications of adding an additional element to it.

If one were to consider just the can self as an independent element, one would expect that the greater the subjective positivity of the can self, the more positive a person would feel. From this perspective, one might expect that people with an actual:ideal discrepancy would be better off if they at least had a can:ideal congruency than if they also had a can:ideal discrepancy. This expectation, however, is based on an "elementistic" logic that assumes that the independent significances of the pair of two-element relations-the level of actual:ideal discrepancy and the level of can:ideal discrepancy-can be simply combined. In contrast, from the holistic perspective of self-discrepancy theory, what is critical is the psychological significance of the pattern as a whole, the multiple-element interrelation among the actual, ideal, and can selves. How does the psychological significance of an actual:ideal discrepancy change whan a can self-belief element is added to the pattern? Because the psychological significance of chronic failure to meet one's ideal depends on the meaning of such failure, it is necessary to consider how the relation of the can self to the actual and ideal selves changes the meaning of an actual:ideal discrepancy.

Let us consider, then, the psychological significance of different patterns involving an actual:ideal discrepancy in combination with the can self.

Actual: can congruency with can:ideal discrepancy $(A=$ $C<I$ ). A can:ideal discrepancy (i.e., $C<I$ ) represents the subjective belief that one's ideal self is beyond one's capability, that one does not have the potential to meet one's ideal. But an actual:can congruency (i.e., $A=C$ ) represents the subjective belief that one is at least fulfilling one's potential. As a whole, then, this pattern of selfbeliefs represents the psychological situation of fulfillment of limited potential.

Actual:can discrepancy with can:ideal congruency [A $<C(=I)]$. A can:ideal congruency (i.e., $C=I$ ) represents the subjective belief that one has the capability, the potential, to meet one's ideal. Given this relation between the can and ideal selves, the can self takes on the meaning of one's positive potential. But the actual self is perceived as being discrepant from the can self (i.e., $A<C)$. As a whole, then, this pattern of self-beliefs represents the psychological situation of chronic failure to meet one's positive potential.

As described, the psychological situation represented by each of these patterns is basically unpleasant. This is to be expected, given that both patterns involve the general absence of positive outcomes represented by an actual:ideal discrepancy. But when one considers the more specific meaning represented by each pattern as a whole, the $A<C(=I)$ pattern is clearly more unpleasant than the $A=C<I$ pattern, even though the can self, as an independent element, is more positive in the former pattern than in the latter pattern. This is because the $A=$ $C<I$ pattern as a whole represents fulfillment of one's 
potential even though the potential is limited, whereas the $A<C(=I)$ pattern as a whole represents a chronic failure to meet one's positive potential. Indeed, the psychological situation of believing that one has failed to meet one's positive potential has been associated with depression in the clinical literature (e.g., Blatt, D'Afflitti, \& Quinlan, 1976). And Bandura (1986) suggests that people with high self-perceived capability who experience repeated failure are especially likely to become depressed.

Thus, contrary to what one would predict from an elementistic perspective, we predicted that possession of an $A<C(=I)$ pattern would be associated with greater dejection-related emotions than would possession of an $A=C<I$ pattern. This prediction has been tested in a study by Higgins, Tykocinsky, and Vookles (1990). As part of filling out the "Selves Questionnaire," subjects were asked to "list the attributes of the type of person you think you can be, have the potential or capability to be," after being asked to list their actual self-attributes and before listing their ideal self-attributes. Thus, it was possible to identify different patterns by measuring both subjects' can:ideal and actual:can discrepancies. For example, when people's can selves are congruent with their ideal selves (i.e., $C=I$ ), but their actual selves are discrepant with their can selves (i.e., $A<C$ ), then they possess an actual:ideal discrepancy involving the $A<C(=I)$ pattern. Our procedure for calculating self-discrepancy patterns in this study was more configurational than that used in our previous studies. For each of the two types of actual:ideal discrepancy patterns described abovethe $A=C<I$ pattern and the $A<C(=I)$ pattern-a subject's attribute responses to all three self-belief elements in a particular pattern were considered together.

We predicted that although the $C=I$ unit was more positive than the $C<I$ unit, the $A<C(=I)$ pattern would be associated with more suffering than would the $A=C<I$ pattern. As is shown in Table 2, this prediction was confirmed. Indeed, the partial correlations (shown in the right half of Table 2 ) indicate that only the $A<C(=I)$ pattern was uniquely associated in general with dejection-related emotions and beliefs. The $A<$ $C(=I)$ pattern as a whole represents the negative psychological situation of chronic failure to meet one's positive potential. Consistent with this specific meaning, the $A<C(=I)$ pattern was uniquely associated with "feeling like a failure"; not feeling "satisfied with myself and my accomplishments," "energetic," or "self-controlled"; feeling "listless" and "helpless"; and believing that "there is something wrong with me that prevents me from fulfilling my potential" - in general, a "feeling weak" syndrome.

In this paper, the chronic psychological significances associated with the self-system have been considered. Consistent with some basic assumptions of three classic models of knowledge representation-cybernetic theory, cognitive neuroscience theory, and Gestalt psychologyself-discrepancy theory assumes that people store representations of interrelated self-beliefs that function like interconnected assemblies, and that these assemblies, as a whole, have both meaning and importance-that is, specific psychological significances-for those who possess them. The theory proposes that people's interpretations and evaluations of self-relevant life events, whether past, present, or future, are influenced by these holistic self-belief patterns. Thus, the same event can produce different emotional and motivational responses in different people or even in the same person at different times, depending on which particular type of self-belief pattern is activated by the event. This proposal has received considerable support. There is now substantial evidence that

Table 2

Predictive Relations to Dejection-Related Symptoms and Beliefs of Two Types of Actual:Ideal Discrepancy Patterns Involving the Can Selfthe $A<C(=I)$ Pattern and the $A=C<I$ Pattern

\begin{tabular}{|c|c|c|c|c|}
\hline \multirow[b]{2}{*}{ Symptoms and Beliefs } & \multicolumn{2}{|c|}{ Zero-Order Correlations } & \multicolumn{2}{|c|}{ Partial Correlations } \\
\hline & $\mathrm{A}=C<I$ & $A<C(=I)$ & $A=C<I$ & $A<C(=I)$ \\
\hline$\overline{\mathrm{BDI}}$ & $.25^{*}$ & $.36 \ddagger$ & -.01 & $.27 \dagger$ \\
\hline Feel like a failure & .14 & $.35 \ddagger$ & .15 & $.35 \ddagger$ \\
\hline $\begin{array}{l}\text { Not satisfied with } \\
\text { myself and my } \\
\text { accomplishments }\end{array}$ & .11 & $.24 *$ & -.08 & $.23 *$ \\
\hline Have to push myself to & & & & \\
\hline do anything & .18 & $.43 \ddagger$ & -.17 & $.42 \ddagger$ \\
\hline (Not) Driven & -.03 & $.30 \dagger$ & -.08 & $.27 \dagger$ \\
\hline (Not) Alert & .09 & $.21 *$ & -.08 & $.21^{*}$ \\
\hline Listless & $.25^{*}$ & $.31 \dagger$ & .05 & $.20 *$ \\
\hline (Not) Energetic & .09 & $.28 \dagger$ & -.14 & $.30 \dagger$ \\
\hline $\begin{array}{l}\text { There is something } \\
\text { wrong with me that } \\
\text { prevents me from }\end{array}$ & & & & \\
\hline fulfilling my potential & .08 & $.26 \dagger$ & -.14 & $.28 \dagger$ \\
\hline (Not) Self-controlled & .12 & $.23 *$ & -.05 & $.20^{*}$ \\
\hline Helpless & .17 & $.33 \ddagger$ & -.08 & $.30 \dagger$ \\
\hline
\end{tabular}

${ }^{*} p<.05 . \quad \dagger p<.01 . \quad \ddagger p<.001$. 
different types of self-belief patterns are associated with vulnerability to distinct kinds of emotional and motivational problems.

\section{REFERENCES}

BAndura, A. (1982). The self and mechanisms of agency. In J. Suls (Ed.), Psychological perspectives on the self (Vol. 1, pp. 3-39). Hillsdale, NJ: Erlbaum.

BANDURA, A. (1986). Social foundations of thought and action: A social cognitive theory. Englewood Cliffs, NJ: Prentice-Hall.

Blatt, S. J., D’Affltti, J. P., \& Quinlan, D. M. (1976). Experiences of depression in normal young adults. Journal of Abnormal Psychology, 86, 203-223.

HeBb, D. O. (1949). The organization of behavior. New York: Wiley. HigGins, E. T. (1987). Self-discrepancy: A theory relating self and affect. Psychological Review, 94, 319-340.

Higgins, E. T. (1989a). Knowledge accessibility and activation: Subjectivity and suffering from unconscious sources. In J. S. Uleman \& J. A. Bargh (Eds.), Unintended thought (pp. 75-123). New York: Guilford Press.

Higgins, E. T. (1989b). Self-discrepancy theory: What patterns of selfbeliefs cause people to suffer? In L. Berkowitz (Ed.), Advances in experimental social psychology (Vol. 22, pp. 93-136). New York: Academic Press.

Higgins, E. T., Bond, R. N., Klein, R., \& Strauman, T. (1986). Self-discrepancies and emotional vulnerability: How magnitude, accessibility, and type of discrepancy influence affect. Journal of Personality \& Social Psychology, 51, 5-15.

Higgins, E. T., Tykocinsky, O., \& Vookles, J. (1990). Patterns of self-beliefs: The psychological significance of relations among the actual, ideal, ought, can, and future selves. In J. M. Olson \& M. P. Zanna (Eds.), Self-inference processes: The Ontario Symposium (Vol. 6, pp. 153-190). Hillsdale, NJ: Erlbaum.

James, W. (1948). Psychology. New York: World Publishing. (Original work published 1890)

KOHLER, W. (1929). Gestalt psychology. New York: Liveright.

KofFKA, K. (1935). Principles of Gestalt psychology. New York: Harcourt, Brace.

Markus, H., \& Nurius, P. (1986). Possible selves. American Psychologist, 41, 954-969.

MARKUS, H., \& WURF, E. (1987). The dynamic self-concept: A social psychological perspective. Annual Review of Psychology, 38, 299-337.

Strauman, T. J., \&igins, E. T. (1987). Automatic activation of self-discrepancies and emotional syndromes: When cognitive structures influence affect. Journal of Personality \& Social Psychology, 53, 1004-1014.

WiEnER, N. (1948). Cybernetics: Control and communication in the animal and the machine. Cambridge, MA: MIT Press. 